\title{
Improvement of Peach Embryo Culture Through Manipulation of Carbohydrate Source and pH
}

\author{
Jonathan W. Sinclair ${ }^{1}$ and David H. Byrne ${ }^{2}$ \\ Department of Horticultural Sciences, Texas A\&MUniversity, College Station, \\ TX 77843-2133
}

Additional index words. tissue culture, MES, buffer, sugar, embryo rescue

\begin{abstract}
Carbohydrate source of peach [Prunus persica $\left(L_{\text {. }}\right)$ Batsch] embryo culture media affects embryo growth and survival. The first objective of this study was to determine the effect of five carbohydrates (fructose, glucose, maltose, sorbitol, and sucrose) in Woody Plant Medium (WPM) on the germination and survival of peach embryos in vitro. Fructose, glucose, maltose, and sucrose in WPM resulted in better embryo germination and survival than sorbitol. Fructose $(2 \%$ and $3 \%)$ produced greater survival than all other carbohydrates tested in smaller embryos ( $<10 \%$ ovule dry weight $)$. However, sucrose was better than all other carbohydrates tested in the larger embryos ( $\geq 10 \%$ ovule dry weight). In addition, large embryos ( $>10 \%$ ovule dry weight) on fructose at $1 \%$ combined with glucose, maltose, sorbitol, or sucrose at $1 \%$ had equivalent or higher survival than did those on either $1 \%$ or $2 \%$ sucrose in conjunction with the same carbohydrates. Embryo survival on different carbohydrates varied with genotype. The second objective of this study was to determine the effect of three levels of MES buffer $(0.0 \mathrm{~mm}, 4.5 \mathrm{~mm}$, and $9.0 \mathrm{~mm}$ ) on medium pH stability and embryo survival. MES buffer at $0.0 \mathrm{~mm}$ and 4.5 mu concentration produced significantly better embryo survival than $9.0 \mathrm{~mm}$. The pH stability was better at MES $9.0 \mathrm{~mm}$, however survival decreased significantly. Chemical name used: [2-(N-morpholino)-ethane sulphonic acid] (MES)
\end{abstract}

Commercially productive, low-chill, earlyripening peach [Prunus persica (L.) Batsch] cultivars are important in the United States because they are marketed in April and May (Sherman and Rodriguez, 1987) when the supply of fresh peaches is low and the price is about twice that of peaches harvested in late June and July [U.S. Dept. of Agriculture (USDA), 1995].

A major problem with breeding earlyripening peach cultivars is the failure of seed germination. Aseptic embryo culture in a nutrient-rich environment can overcome this problem (Brooks and Hough, 1958). Sucrose (2\% to $5 \%$ ) is the most popular carbohydrate used with tissue culture (Brigden, 1994). However, other sources, such as fructose, glucose, maltose, and sorbitol, have proven more effective than sucrose in various tissue culture studies (Batty and Dunwell, 1989; Hammatt, 1993; Marino et al., 1993; Scozzoli and Pasini, 1992).

Embryo culture media used in peach breeding programs must produce acceptable survival on a wide range of early-ripening genotypes to be of practical use since it is not feasible to develop a different medium for each individual genotype. Although these genotypes ripen in April through mid June in Texas, previous work indicates that the most important factor in success of a medium is embryo maturity as measured by size or ovule percent dry weight (Bacon and Byrne, 1995; Burgos and Ledbetter,

Received for publication 12 Feb. 2002. Accepted for publication 18 July 2002. The assistance of Kilsun Yoo in the analysis of sugar content in the media is gratefully acknowledged.

${ }^{1}$ Graduate Student.

${ }^{2}$ Professor.
1993; Kester and Hesse, 1955). At present, the most common procedure is to culture small embryos (5-10 mm) in Woody Plant Medium (WPM) (Lloyd and McCown, 1981), with 3\% sucrose and larger embryos $(>10 \mathrm{~mm})$ in WPM with 2\% sucrose (Chaparro and Sherman, 1994; Ramming, 1985; Rizzo et al., 1998).

The $\mathrm{pH}$ of tissue culture media can affect plant growth (Almehdi and Parfitt, 1986; Emershad and Ramming, 1994; Reeves et al., 1983). Plants effectively alter the $\mathrm{pH}$ of their culture medium in the normal process of growth by releasing $\mathrm{H}^{+}$in response to cation adsorption (e.g., $\mathrm{K}^{+}$or $\mathrm{NH}_{4}^{+}$) or by ammonium depletion in the medium (Bonga and Aderkas, 1992). Extreme pH differences close to the root surface may negatively affect the uptake of mineral nutrients (Frick and Mitchell, 1993), thus limiting growth and differentiation. MES is a promising $\mathrm{pH}$ buffer for use with embryo culture of peaches because it is biologically inert and non-interactive with medium ions (Bugbee and Salisbury, 1985).

The overall objectives of this study were to determine the effects of carbohydrate source and $\mathrm{pH}$ of embryo culture medium on germination and survival of immature peach embryos of varying sizes.

\section{Materials and Methods}

Healthy, well-developed fruit of 10 genotypes ('Flordaking', 'Flordacrest', TX5B5, TX 4392-6, 'Springprince', TX5393-1, 'Scarletpearl', TX4393-5, TX3189-1, and TX4D46W) was harvested from late April through late June, depending upon individual genotype maturation and stored at $4{ }^{\circ} \mathrm{C} \pm 1{ }^{\circ} \mathrm{C}$ for a period of
$<14 \mathrm{~d}$ before use. Standard sterilization and culture procedures were followed (Rizzo et al., 1998). Ovule/embryo size and ovule percent dry weight were determined prior to culturing with destructive measurements on a representative sample of 10 ovules per genotype.

Fruit was first surface sterilized. Under sterile conditions ovules were extracted, seed coats removed, and the embryos were placed into $25 \times 95 \mathrm{~mm}$ Baxter shell vials containing $10 \mathrm{~mL}$ of WPM medium. Ten to 18 replications (embryos) per treatment were used in all experiments $(n=10$ to 18$)$. Racks of vials containing medium and embryos were sealed in large paper bags (randomly) and stratified in the dark at $4{ }^{\circ} \mathrm{C}$ for $\approx 10$ weeks, after which time they were removed and placed under fluorescent lighting at $\approx 8.6$ klux with a 16 -h photoperiod at $28 \pm 1{ }^{\circ} \mathrm{C}(1998)$ or $18 \pm 2{ }^{\circ} \mathrm{C}$ (1999) to induce germination. After $\approx 3$ weeks when the plants had both adequate shoot and root formation for survival out of culture, they were transferred to planting medium (Sunshine Mix \#4, Sun Gro, Belleview, Wash.) in $25 \times$ $52 \times 7 \mathrm{~cm}$ trays with humidity domes and grown under artificial fluorescent lighting at $\approx 8.6$ klux with a 16 -h photoperiod at 28 ${ }^{\circ} \mathrm{C} \pm 1{ }^{\circ} \mathrm{C}$. Humidity domes were removed after 2-3 d. After 2 to 3 weeks under lights in the laboratory, plants were transferred to mist benches in the greenhouse and left for $\approx 1$ week. When the shoots were $\approx 10 \mathrm{~cm}$ long, they were planted into $5.1 \times 6.4 \times 25.4$ $\mathrm{cm}$ Roottrainers (Spencer-Lemaire, Alberta, Canada). Germination data were recorded on the number of embryos that developed both adequate roots and shoots. Survival data was taken on the number of plants that survived transfer to Roottrainers in the greenhouse.

1998 carbohydrate source experiment. The basal medium was WPM nutrients and vitamins, (Lloyd and McCown, 1981) (pH6.00 \pm 0.01 and $4.5 \mathrm{~mm}$ MES added as a buffer). The effects of the five carbohydrates (fructose, glucose, maltose, sorbitol, and sucrose) at $2 \%$ and $3 \%$ (10 treatments) were examined on five peach genotypes ('Flordacrest', TX5B5, TX4392-6, 'Springprince', and three successive harvests at 1-week intervals of 'Flordaking') in a factorial experiment.

1999 fructose, sucrose, or both combination experiment. The effects of WPM containing either $1 \%$ fructose or $1 \%$ or $2 \%$ sucrose in conjunction with either $1 \%$ glucose, maltose, sorbitol, or sucrose (12 treatments) were examined on three peach genotypes ('Flordacrest', TX4392-6, and TX4D46W) in a factorial experiment.

$1998 \mathrm{pH}$ experiment. The effects of MES at three concentrations $(0.0,4.5$, and $9.0 \mathrm{~mm})$ and two $\mathrm{pH}$ levels (5.7 or 6.0) were examined on four genotypes ('Springprince', TX5393-1, 'Scarletpearl', and TX4393-5) with WPM containing $3 \%$ sucrose in a factorial experiment.

Survival data was taken in a binomial format $(0=$ dead and $1=$ alive $) \approx 4$ weeks after removal from stratification. Treatment effects in carbohydrate experiments (genotype, carbohydrate source, and carbohydrate concentration) and in $\mathrm{pH}$ experiments (genotype, $\mathrm{pH}$ level, and MES concentration) were analyzed 
as factorials using the SAS GLM and Duncan's multiple range test (SAS, 1985).

\section{Results and Discussion}

Since previous reports indicated that sucrose and fructose degraded upon autoclaving (Owen et al., 1991; Schenk et al., 1991), the carbohydrate concentrations were measured by liquid chromatography before and after autoclaving. Autoclaving was not found to substantially degrade any of the carbohydrates used (data not shown).

1998 carbohydrate source experiment. The genotypes tested were grouped into two categories. Small embryos ( $<10 \%$ ovule dry weight) were from peach genotypes TX5B5 (7.8\% ovule dry weight, $10.8 \mathrm{~mm}$ embryo length), 'Flordaking' first harvest ( $8.3 \%$ ovule dry weight, $9.7 \mathrm{~mm}$ embryo length), and 'Flordaking second harvest $(9.8 \%$ ovule dry weight, $10.2 \mathrm{~mm}$ embryo length). Large embryos ( $\geq 10 \%$ ovule dry weight) were from peach genotypes 'Flordaking' third harvest (10.0\% ovule dry weight, $10.4 \mathrm{~mm}$ embryo length), TX4392-6 (11.2\% ovule dry weight, $11.8 \mathrm{~mm}$ embryo length), 'Springprince' (11.6\% ovule dry weight, $11.9 \mathrm{~mm}$ embryo length), and 'Flordacrest' (11.9\% ovule dry weight, $10.6 \mathrm{~mm}$ embryo length). Survival was influenced by genotype and carbohydrate source main effects as well as the genotype $x$ carbohydrate source, carbohydrate source $x$ carbohydrate concentration, and genotype $x$ carbohydrate source $\times$ carbohydrate concentration interactions (Table 1).

Across all genotypes and carbohydrate treatments, immature peach embryos germinated, grew, and survived best with fructose, maltose, and sucrose. The use of sorbitol gave the lowest percent survival and glucose was intermediate (Table 2). Sorbitol may have resulted in poor survival because the embryos may not be able to efficiently metabolize sorbitol once the seed coat is removed, since most of the enzyme sorbitol oxidase, which converts sorbitol to glucose, is produced in the seed coat (Yamaki and Ryugo, 1986). Although sucrose is the most popular carbohydrate for tissue culture, it alone is not necessarily the best for peach embryo culture.

The genotype survival ranged from $25 \%$ for the earliest harvested 'Flordaking' embryos to $56 \%$ for 'Springprince' (data not shown). This is in part related to embryo size as indicated by the lower survival $(25 \%)$ of the smallest 'Flordaking' embryos (first harvest) compared to the larger 'Flordaking' embryos that were harvested 1 and 2 weeks later (33\% to $39 \%)$ ).

The interaction between carbohydrate source and the carbohydrate concentration was primarily due to differential survival of embryos on the two separate concentrations of maltose and sucrose (Table 2). Normally, $2 \%$ to $3 \%$ sucrose is used in peach embryo culture based upon embryo size with the lower carbohydrate concentration better for the larger embryo sizes (Chaparro and Sherman, 1994; Ramming, 1985; Rizzo et al., 1998). Further examination of the data by embryo size indicated that small embryo $(<10 \%$ ovule dry
Table 1. Percent germination and survival of immature peach embryos influenced by genotype ${ }^{\mathrm{z}}$, carbohydrate source ${ }^{\mathrm{y}}$, and carbohydrate concentration ${ }^{\mathrm{x}}$ in 1998.

\begin{tabular}{lrcc}
\hline Variation & df & Germination & Survival \\
\hline Genotype & 6 & $* * *$ & $* * *$ \\
Carbohydrate source & 4 & $* * *$ & $* * *$ \\
Carbohydrate concentration & 1 & NS & NS \\
Genotype $\times$ carbohydrate source & 24 & $* * *$ & $* *$ \\
Genotype $\times$ carbohydrate concn & 6 & $* *$ & NS \\
Carbohydrate source $\times$ carbohydrate concn & 4 & $* * *$ & $* * *$ \\
Genotype $\times$ carbohydrate source $\times$ carbohydrate concn & 24 & $*$ & $* *$ \\
Total & 1019 & & \\
\hline
\end{tabular}

"'Springprince', $\mathrm{n}=16$; 'Flordacrest', $\mathrm{n}=12$; 'Flordaking', (three harvests) $\mathrm{n}=10,18,18$; TX4392-6, $\mathrm{n}=16$; TX5B5, $\mathrm{n}=12$ ( $\mathrm{n}$ indicates the number of embryos from each genotype used with each treatment combination).

${ }^{\mathrm{y}}$ Fructose, glucose, maltose, sorbitol, and sucrose.

$\times 2 \%$ and $3 \%$.

Ns*,******Nonsignificant or significant at $P \leq 0.05,0.01,0.001$, respectively.

Table 2. Survival of immature peach embryos related to carbohydrate source and interactions with carbohydrate concentration and embryo size in 1998. Combined data from 'Flordaking' (three harvests), TX5B5, 'Springprince', 'Flordacrest', and TX4392-6 were used.

\begin{tabular}{lccccc}
\hline & \multicolumn{5}{c}{ Carbohydrate source } \\
\cline { 2 - 6 } & Fructose & Glucose & Maltose & Sorbitol & Sucrose \\
\hline Survival (\%) & $54 \mathrm{a}^{\mathrm{z}}$ & $40 \mathrm{~b}$ & $45 \mathrm{ab}$ & $10 \mathrm{c}$ & $52 \mathrm{a}$ \\
$2 \%$ carbohydrate & $54 \mathrm{ab}$ & $44 \mathrm{bc}$ & $32 \mathrm{c}$ & $12 \mathrm{~d}$ & $64 \mathrm{a}$ \\
$3 \%$ carbohydrate & $55 \mathrm{ab}$ & $38 \mathrm{c}$ & $61 \mathrm{a}$ & $9 \mathrm{~d}$ & $43 \mathrm{bc}$ \\
$<10 \%$ ovule dry weight $\mathrm{y}, \mathrm{x}$ & $65 \mathrm{a}$ & $34 \mathrm{c}$ & $43 \mathrm{~b}$ & $10 \mathrm{~d}$ & $33 \mathrm{c}$ \\
$>10 \%$ ovule dry weight & $48 \mathrm{~b}$ & $46 \mathrm{~b}$ & $49 \mathrm{~b}$ & $10 \mathrm{~d}$ & $67 \mathrm{a}$ \\
\hline
\end{tabular}

${ }^{2}$ Different letters following values indicate significant differences within rows according to Duncan's multiple range test $(P \leq 0.05)$.

'The smaller embryos ( $<10 \%$ ovule dry weight) were from 'Flordaking' (first two harvests), $\mathrm{n}=10,18$ and TX5B5, $\mathrm{n}=12$. The larger embryos ( $>10 \%$ ovule dry weight) were from 'Flordaking' (third harvest), $\mathrm{n}=18$; 'Springprince', $\mathrm{n}=16$; 'Flordacrest', $\mathrm{n}$ $=12$; and TX4392-6, $\mathrm{n}=16$ ( $\mathrm{n}$ indicates the number of embryos from each genotype used with each treatment combination).

${ }^{x}$ Percent dry weight was determined with destructive measurements on a representative sample of 10 ovules per genotype.

\section{$1 \%$ Fructose $1 \%$ Sucrose $2 \%$ Sucrose}

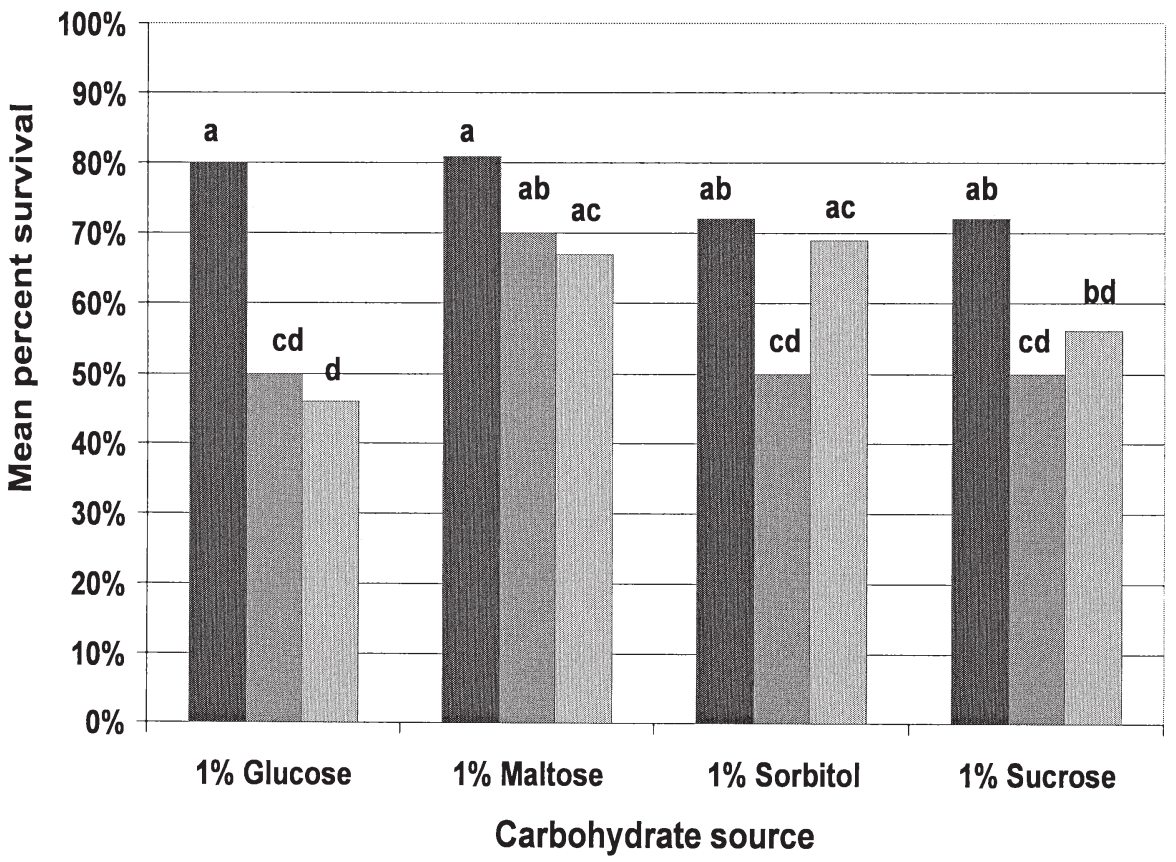

Fig. 1. Comparison of mean survival for immature peach embryos (all $>10 \%$ ovule dry weight) over three genotypes (TX4D46W, $\mathrm{n}=18$; 'Flordacrest', $\mathrm{n}=18$; and TX4392-6, $\mathrm{n}=18$ ) on WPM containing either $1 \%$ fructose or $1 \%$ or $2 \%$ sucrose in combination with $1 \%$ glucose, maltose, sorbitol, or sucrose (1999 experiments). Different letters indicate significant differences according to Duncan's multiple range test $(P \leq 0.05)$. 
weight) survival is better on fructose and large embryo ( $>10 \%$ ovule dry weight) survival is better on sucrose (Table 2). Whereas there are reports that genotype (Brigden, 1994), sugar carbohydrate type (Hammatt, 1993; Scozzoli and Pasini, 1992), and embryo size (Kester and Hesse, 1955; Ramming, 1990) may affect plant growth in vitro, this is the first report of a differential carbohydrate type effect related to embryo size in peach.

1999 fructose, sucrose, or both combination experiment. All genotypes used had relatively large embryos ( $>10 \%$ ovule dry weight). Their size ranged from $12.6 \%$ to $20.3 \%$ ovule dry weight and 13.0 to $13.3 \mathrm{~mm}$ embryo length. Carbohydrate concentration affected immature peach embryo survival (Fig. 1). One percent fructose in conjunction with $1 \%$ glucose or $1 \%$ maltose produced better embryo survival than either $2 \%$ or $3 \%$ sucrose, the most common carbohydrate concentrations used in peach embryo culture (Chaparro and Sherman, 1994; Ramming, 1985).

All fructose combinations ( $1 \%$ fructose with either glucose, maltose, sorbitol, or sucrose each at $1 \%$ ) produced embryo survival greater than or equal to the sucrose combinations (1\% and $2 \%$ sucrose with either glucose, maltose, sorbitol, or sucrose each at $1 \%$ ) for immature peach embryos $>10 \mathrm{~mm}$ in length (Fig. 1).

Although the genotype $\times$ carbohydrate source combination interaction was significant (Table 3), there were no clear trends. The interaction was accounted for by only 3 of the 12 carbohydrate combinations. This is important because, to be widely used, embryo culture must produce acceptable survival on a wide range of genotypes that produce immature embryos.

These experiments indicate that carbohydrate combinations - especially those including fructose-have the potential to produce higher embryo survival than the standard approach of using one carbohydrate source (sucrose) in the media.

$1998 \mathrm{pH}$ experiment. All genotypes used had relatively large embryos ( $>10 \%$ ovule dry weight). Their size ranged from $11.6 \%$ to $23.2 \%$ ovule dry weight and 11.9 to $14.7 \mathrm{~mm}$ embryo length. Although genotypic survival differed significantly (50\% to $80 \%)$ as expected and MES concentration was also significant, no differences in survival were caused by the two $\mathrm{pH}$ levels (5.7 and 6.0) (Table 4). This was most likely due to the narrow $\mathrm{pH}$ range tested and was in line with previous studies on Vitis somatic embryos ( $\mathrm{pH}$ range 5.0 to 6.0) in which $\mathrm{pH}$ had no effect on average number of surviving embryos (Emershad and Ramming, 1994) and on peach rootstock ( $\mathrm{pH}$ range 5.2 to 5.8) which showed no $\mathrm{pH}$ effect on mortality, but agar medium at $\mathrm{pH} 5.8$ was best for growth (Reeves et al., 1983).

The addition of MES at both the $4.5 \mathrm{~mm}$ and $9.0 \mathrm{~mm}$ concentrations stabilized medium $\mathrm{pH}$ to within $0.5 \mathrm{pH}$ units over a 10 -week period compared to a $>1.0 \mathrm{pH}$ unit change without the MES buffer. Previous studies (Bugbee and Salisbury, 1985; Harbage and Stimart, 1996; Owen et al., 1991) were short-lived compared

Table 3. Germination and survival of immature peach embryos cultured in vitro influenced by genotype ${ }^{z}$ and carbohydrate source combination ${ }^{y}$ in 1999 .

\begin{tabular}{lrcc}
\hline Variation & df & Germination & Survival \\
\hline Genotype & 2 & $* * z$ & NS \\
Carbohydrate source combination & 11 & $* * *$ & $* * *$ \\
Genotype $\times$ carbohydrate source combination & 22 & $* *$ & $* *$ \\
Total & 647 & & \\
\hline
\end{tabular}

${ }^{u}$ Flordacrest, $\mathrm{n}=18$; TX4392-6, $\mathrm{n}=18$; TX4D46W, $\mathrm{n}=18$ ( $\mathrm{n}$ indicates the number of embryos from each genotype used with each treatment combination).

${ }_{1}^{\mathrm{y}} 1 \%$ and $2 \%$ sucrose and $1 \%$ fructose in combination with $1 \%$ glucose, maltose, sorbitol, or sucrose.

Ns, *,******NNonsignificant or significant at $P \leq 0.05,0.01$, and 0.001 , respectively.

Table 4. Germination and survival of embryo cultured immature peach embryos influenced by genotype ${ }^{z}, \mathrm{pH}$ levely, and MES concentration ${ }^{\mathrm{x}}$ in 1998.

\begin{tabular}{|c|c|c|c|}
\hline Variation & $\mathrm{df}$ & Germination & Survival \\
\hline Genotype & 3 & ** & **** \\
\hline pH level & 1 & NS & NS \\
\hline MES concn & 2 & $* * *$ & $* * *$ \\
\hline Genotype $\times \mathrm{pH}$ level & 3 & NS & NS \\
\hline Genotype $\times$ MES concn & 6 & NS & NS \\
\hline $\mathrm{pH}$ level $\times$ MES concn & 2 & NS & NS \\
\hline Genotype $\times \mathrm{pH}$ level $\times$ MES concn & 6 & NS & NS \\
\hline Total & 381 & & \\
\hline \multicolumn{4}{|c|}{$\begin{array}{l}\text { z'Springprince', } \mathrm{n}=14 ; \mathrm{TX} 5393-1, \mathrm{n}=16 \text {; 'Scarletpearl', } \mathrm{n}=16 ; \mathrm{TX} 4393-5 \\
\mathrm{n}=16 \text { ( } \mathrm{n} \text { indicates the number of embryos from each genotype used with each } \\
\text { treatment combination). } \\
\text { y } 5.7 \text { or } 6.0 \text {. } \\
{ }^{\mathrm{x}} 0.0,4.5 \text {, or } 9.0 \mathrm{~mm} \text { concentrations. } \\
\mathrm{Ns,*,**,***} \text { Nonsignificant or significant at } P \leq 0.05,0.01 \text {, and } 0.001 \text {, respectively }\end{array}$} \\
\hline
\end{tabular}

to the 10 weeks of cold storage required for peach embryo culture. It is not surprising that the drop in $\mathrm{pH}$ associated with this experiment was more pronounced $(0.20$ to $1.54 \mathrm{pH}$ units compared to 0.03 to $0.35 \mathrm{pH}$ units from those prior experiments).

Autoclaving significantly alters the $\mathrm{pH}$ of medium (Schenk etal., 1991). In peach-embryo culture experiments, autoclaving lowered the

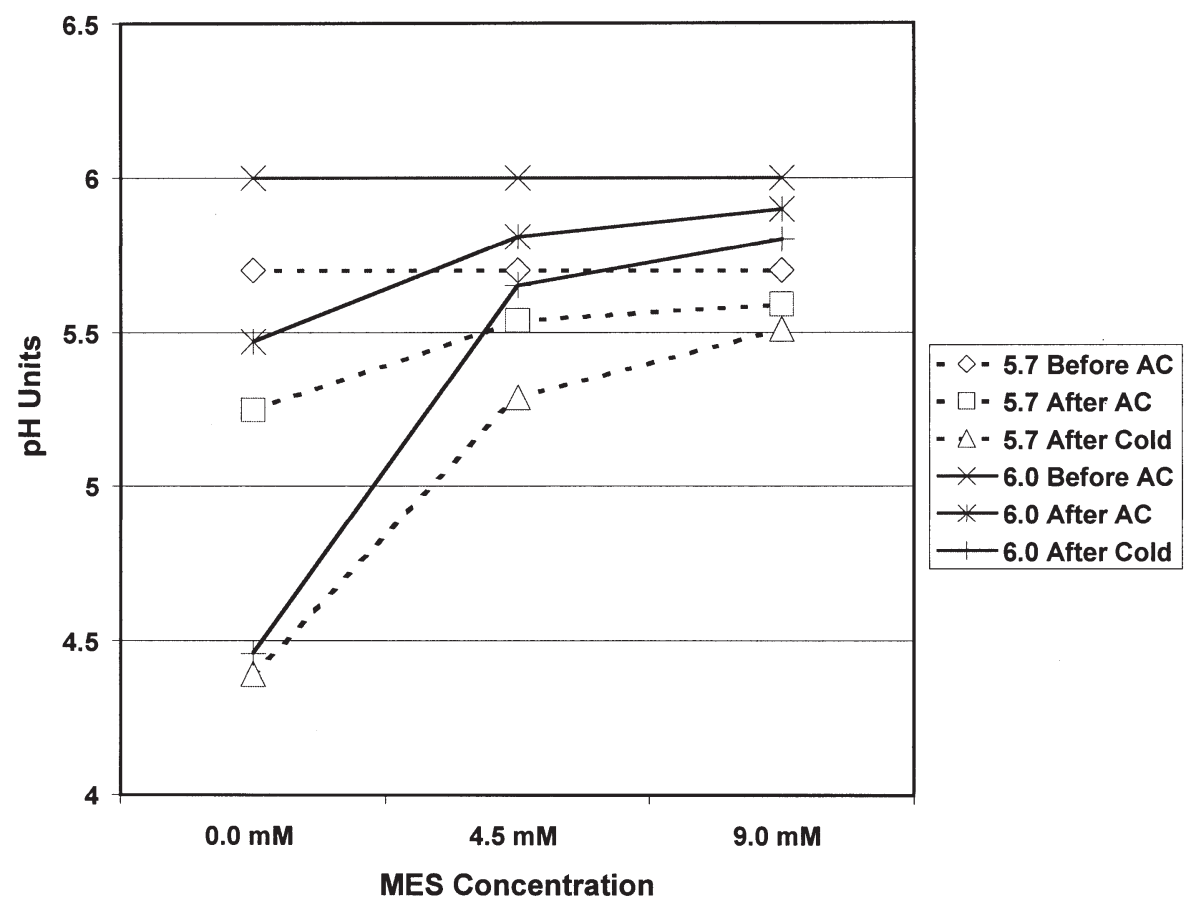

Fig. 2. MES concentration related to $\mathrm{pH}$ stability of Woody Plant Medium before autoclaving (AC), after $\mathrm{AC}$, and after a 10-week period of cold storage (Cold) in 1998. (Beginning pH levels of 5.7 and 6.0 respectively). Fourteen to 16 peach embryos from each of four genotypes ('Springprince' $n=14$, TX5393-1 $n=16$, 'Scarletpearl' $n=16$, and TX4393-5 $n=16$ ) were used per treatment. 
Table 5. Percent survival of immature peach embryos of four genotypes related to two $\mathrm{pH}$ levels and three MES concentrations in 1998.

\begin{tabular}{lccccc}
\hline & \multicolumn{4}{c}{ Genotype } & \\
\cline { 2 - 5 } & Springprince & TX5393-1 & Scarletpearl & TX4393-5 & Mean values $^{\mathrm{z}}$ \\
\hline Embryo length (mm) & 11.9 & 14.5 & 14.7 & 13.7 & 13.7 \\
Ovule \% dry weight & 11.6 & 17.0 & 23.2 & 13.5 & 16.3 \\
\% survival & $50 \mathrm{~b}^{\mathrm{x}}$ & $51 \mathrm{~b}$ & $52 \mathrm{~b}$ & $80 \mathrm{a}$ & 58.3 \\
pH 5.7 & $56 \mathrm{a}^{\mathrm{w}}$ & $58 \mathrm{a}$ & $58 \mathrm{a}$ & $76 \mathrm{a}$ & $61 \mathrm{a}$ \\
pH 6.0 & $48 \mathrm{a}$ & $41 \mathrm{a}$ & $43 \mathrm{a}$ & $83 \mathrm{a}$ & $55 \mathrm{a}$ \\
MES 0.0 mM & $60 \mathrm{a}$ & $50 \mathrm{a}$ & $60 \mathrm{a}$ & $88 \mathrm{a}$ & $65 \mathrm{a}$ \\
MES 4.5 mM & $63 \mathrm{a}$ & $56 \mathrm{a}$ & $60 \mathrm{a}$ & $88 \mathrm{a}$ & $67 \mathrm{a}$ \\
MES 9.0 mM & $34 \mathrm{~b}$ & $44 \mathrm{a}$ & $34 \mathrm{~b}$ & $63 \mathrm{~b}$ & $44 \mathrm{~b}$ \\
\hline
\end{tabular}

${ }_{\mathrm{z}}$ Mean value of each row respectively

y Ovule percent dry weight was determined with destructive measurements on a representative sample of 10 ovules per genotype.

'Different letters following values indicate significant differences within the row according to Duncan's multiple range test $(P \leq 0.05)$.

wDifferent letters following values indicate significant differences within columns according to Duncan's multiple range test $(P \leq 0.05)$.

not with beans (Phaseolus vulgaris L.), corn (Zea mays, L.), lettuce (Latucia sativum, L.), and tomatoes (Lycoperscion esculentum Mill.) (Bugbee and Salisbury, 1985). Consequently, the effect appears related to species sensitivity, period of storage/exposure time, or both. Although promising as a $\mathrm{pH}$ buffer, MES is not recommended for immature peach embryo culture except at low concentrations.

These experiments indicate that for small embryos ( $<10.0 \%$ ovule dry weight) fructose ( $2 \%$ to $3 \%$ ) is better than similar levels of glucose, maltose, sorbitol, or sucrose. For larger embryos ( $>10.0 \%$ ovule dry weight) no single treatment was better than all the rest, but sugar combinations of $1 \%$ fructose combined with other sugars (either glucose, maltose, sorbitol, or sucrose each at $1 \%$ ) were better than or equal to sucrose alone or in combinations.

\section{Literature Cited}

Almehdi,A.A. and D.E. Parfitt. 1986. In vitro propagation of peach: I. Propagation of 'Lovell' and 'Nemaguard' peach rootstocks. Fruit Var. J. 40: 12-17.

Bacon, T.A. and D.H. Byrne. 1995. Relationships of fruit development period, seed germination, seedling survival, and percent dry weight of ovule in peach. HortScience 30:833. (Abstr.)

Batty, N. and J. Dunwell. 1989. Effect of maltose on the response of potato anthers in culture. Plant
Cell Tiss. Org. Cult. 18:221-226

Bonga, J.M. and P. Aderkas. 1992. In vitro culture of trees. Kluwer Acad., Boston.

Bridgen, M.P. 1994. Areview of plant embryo culture. HortScience 29:1243-1245.

Brooks, H.J. and L.F. Hough. 1958. Vernalization studies with peach embryos. Proc. Amer. Soc. Hort. Sci. 71:95-102.

Bugbee, B.G. and F.B. Salisbury. 1985. An evaluation of MES [2(n-morpholino)ethanesulfonic acid] and amberlite irc-50 as $\mathrm{pH}$ buffers for nutrient solution studies. J. Plant Nutr. 8:567-583.

Burgos, L. and C.A. Ledbetter. 1993. Improved efficiency in apricot breeding: Effects of embryo development and nutrient media on in vitro germination and seedling establishment. Plant Cell Tiss. Org. Cult. 35:217-222.

Chaparro, J.X. and W.B. Sherman. 1994. Culture date and germination procedure affects success of nectarine ovule and embryo culture. Fruit Var. J. 48:173-175.

Emershad, R.L. and D.W. Ramming. 1994. Effects of buffers and $\mathrm{pH}$ on Vitis somatic embryo proliferation and enlargement. In: Proc. Intl. Symp. Table Grape Prod., Amer. Soc. Enol. Viticult. Spec. Iss.: 219:-222.

Frick. J. and C.A. Mitchell. 1993. Stabilization of $\mathrm{pH}$ in solid-matrix hydroponic systems. HortScience 28:981-984.

Hammatt, N. 1993. Micropropagation of fastigiate bird cherry (Prunus padus L.) and adventitious shoot formation from leaves. J. Hort. Sci. 68: 975-981.

Harbage, J.F. and D.P. Stimart. 1996. Effect of pH and $1 H$-indole-3-butryic acid (IBA) on rooting of apple microcuttings. J. Amer. Soc. Hort. Sci. 121:1049-1053.

Kester,D.E. and C.O. Hesse. 1955. Embryo culture of peach varieties in relation to season of ripening. Proc. Amer. Soc. Hort. Sci. 65:265-273.

Lloyd, G. and B. McCown. 1981. Commercially-feasible micropropagation of mountain laurel, $\mathrm{Kal}$ mia latifolia, by use of shoot-tip culture. Comb. Proc. Intl. Plant Prop. Soc. 30:421-427.

Marino, G., G. Bertazza, E. Magnanini, and A.D. Altan. 1993. Comparative effects of sorbitol and sucrose as main carbon sources in micropropagation of apricot. Plant Cell Tiss. Org. Cult. 43: 235-244.

Owen, H.R., D. Wengerd, and A.R. Miller. 1991. Culture medium $\mathrm{pH}$ is influenced by basal medium, carbohydrate source, gelling agent, activated charcoal, and medium storage method. Plant Cell Rpt. 10:583-586.

Ramming, D.W. 1985. In ovulo embryo culture of early maturing Prunus. HortScience 20: 419-420.

Ramming, D.W. 1990. The use of embryo culture in fruit breeding. HortScience. 25:393-398.

Reeves, D.W., B.D. Horton, and G.A. Couvillon. 1983. Effect of media and media $\mathrm{pH}$ on in vitro propagation of 'Nemaguard' peach rootstock. Sci. Hort. 21:353-357.

Rizzo, M., K. Porter, D. Bassi, and D. Byrne. 1998. Growth of immature peach [Prunus persica $(\mathrm{L}$.) Batsch.] embryos on different media. Acta Hort., 465:141-144.

Rys, G.J. and T. Phung. 1985. Nitrogen solution $\mathrm{pH}$ control using dipolar buffer in studies of Trifolium repens L. nitrogen nutrition. J. Exp. Bot. 36:426-431.

SAS Institute, Inc. 1985. SAS user's guide: Statistics, version 5 ed. SAS Inst., Cary, N.C.

Schenk, N., K. Hsiao, and C. H. Bornman. 1991. Avoidance of precipitation and arbohydrate breakdown in autoclaved plant tissue culture media. Plant Cell Rpt. 10:115-119.

Scozzoli, A. and D. Pasini. 1992. Effects of different media constituents on development of peach embryos cultured in vitro. Acta Hort. 300:265-268.

Sherman, W.B. and J. Rodriguez. 1987. Breeding of low-chill peach and nectarine for mild winters. HortScience 22:1233-1236.

U.S. Dept. of Agriculture. 1995. Fruit and tree nuts: Situation and outlook report. USDA Econ. Res. Serv., Washington, D.C.

Yamaki, S. and K. Ryugo. 1986. Peach ovules, a model for studying photosynthate unloading mechanism. HortScience 21:757. (Abstr.) 